\title{
BENEFÍCIOS DOS ALIMENTOS FUNCIONAIS NO CONTROLE E TRATAMENTO DO DIABETES MELLITUS (DM) - REVISÃO DE LITERATURA
}

\section{BENEFITS OF FUNCTIONAL FOODS IN THE CONTROL AND TREATMENT OF DIABETES MELLITUS (DM) - LITERATURE REVIEW}

\author{
Isabela Silva Peres da Conceição \\ Graduada em Ciências Biológicas (bacharelado e licenciatura) \\ Centro Universitário Módulo e Universidade Metropolitana de Santos (UNIMES) \\ isabela peress@hotmail.com \\ Ana Carolina Lacerda Borges \\ Graduada em Fisioterapia e Mestre em Engenharia Biomédica \\ Centro Universitário Módulo \\ ana.borges@modulo.edu.br
}

\section{RESUMO}

O Diabete Mellitus (DM) é uma doença ocasionada pela deficiência na ação ou produção da insulina no pâncreas, atingindo mais de 300 milhões de pessoas mundialmente. Acredita-se que os casos ultrapassem em 2035, mais de 19,2 milhões de pessoas somente no Brasil. Nesse contexto, sabe-se que a alimentação é fator primordial para o tratamento do DM, e que, juntamente com os medicamentos periódicos e atividades físicas, determinarão o controle e uma boa qualidade de vida para os indivíduos diabéticos. Assim, acredita-se que os alimentos funcionais realizem ações metabólicas no organismo, sendo responsáveis por auxiliar neste controle, principalmente na diminuição da glicose na corrente sanguínea. Portanto, esse trabalho tem como objetivo avaliar os benefícios dos alimentos funcionais no controle e tratamento do Diabetes Mellitus (DM). Foi desenvolvido um trabalho de revisão de literatura, iniciado no mês de maio de 2017 e finalizado em novembro de 2017, utilizando como palavras chaves: "Diabetes", "Alimentos Funcionais" e "Tratamento". Os benefícios dos alimentos funcionais no controle e no tratamento do DM estão vinculados à redução da absorção de glicose, da resistência à insulina, da destruição das células beta do pâncreas, contribuindo diretamente na manutenção da glicemia por meio dos compostos funcionais encontrados em diversos alimentos como a aveia, oleaginosas, probióticos, gorduras poliinsaturadas (Ômega 3) e soja. O Biólogo tem papel primordial no que diz respeito às pesquisas vinculadas a essa temática, sendo profissional de destaque, podendo contribuir de forma ativa para o crescimento da ciência.

Palavras-chave: Diabetes. Alimentos Funcionais. Tratamento.

\begin{abstract}
Diabetes Mellitus (DM) is a disease caused by deficiency in the action or production of insulin in the pancreas, reaching more than 300 million people worldwide. It is believed that the cases exceed in 2035, more than 19.2 million people only in Brazil. In this context, it is known that feeding is a primary factor for the treatment of DM, and that, along with periodic medications and physical activities, will determine the control and a good quality of life for diabetic individuals. Thus, it is believed that functional foods perform metabolic actions in the body, being responsible for assisting in this control, mainly in the decrease of glucose in the bloodstream. Therefore, this study aims to evaluate the benefits of functional foods in the control and treatment of Diabetes Mellitus (DM). A literature review was developed, starting in May 2017 and finished in November 2017, using as keywords: "Diabetes", "Functional Foods" and "Treatment". The benefits of functional foods in DM control and treatment are linked to reduced glucose absorption, insulin resistance, destruction of beta cells in the pancreas, contributing directly to the maintenance of glycemia through the functional compounds found in various foods such as oats, oilseeds, probiotics, polyunsaturated fats (Omega 3) and soy. The Biologist plays a fundamental role in the research related to this subject, being a professional of prominence, being able to contribute actively to the growth of science.
\end{abstract}

Keywords: Diabetes. Functional Foods. Treatment.

Recebido em: 06/06/2020

Aceito para publicação em: 01/03/2021.

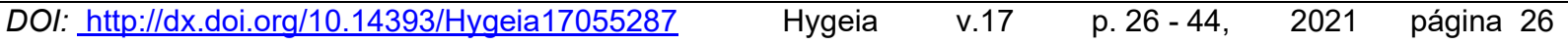




\section{INTRODUÇÃO}

O Diabete Mellitus (DM) é uma doença autoimune decorrente da falta ou deficiência na produção de insulina pelo pâncreas (BRASIL, 2013), que afeta mais de 300 milhões de pessoas em todo mundo (BRITO et al., 2016). Dentre os fatores de risco relacionados ao desenvolvimento do DM, destacam-se a história genética familiar, a obesidade, o sedentarismo e o mau hábito alimentar (SANTOS et al., 2012; ZAPAROLLI et al., 2013).

É sabido que as grandes concentrações de pessoas em regiões urbanas, junto com as praticidades alimentares das comidas industrializadas ricas em açúcar, acabam muitas vezes, deixando os bons hábitos alimentares de lado, e, aliado ao estilo de vida cada vez mais sedentário, têm afetado negativamente não somente as crianças, como também os adultos contemporâneos (BRASIL, 2013).

Considera-se que o desenvolvimento de $70 \%$ das doenças crônicas não transmissíveis está associado à alimentação e ao estilo de vida. A alimentação é classificada como um dos fatores mais relevantes para o controle e tratamento do DM, sendo em algumas situações, a única intervenção necessária. Diversos estudos confirmam que existe uma pluralidade de alimentos que apresentam substâncias benéficas que agem na prevenção e/ou controle de doenças como o DM e suas complicações (ZAPAROLLI et al., 2013). Sabe-se que um acompanhamento nutricional que reforce o aumento de frutas, vegetais, grãos e a diminuição de gorduras saturadas na dieta e a escolha de hábitos de vida saudáveis, como a prática regular de atividade física, são essenciais para a prevenção do DM e melhora na qualidade de vida (NAKAGAKI; MCLELLAN, 2013).

Os alimentos funcionais são caracterizados pelas ações metabólicas e/ou fisiológicas que um nutriente como a fibra, ou não nutriente como o licopeno, pode desemp3enhar no organismo de uma pessoa, no desenvolvimento, manutenção, crescimento e outras diversas funções. Desse modo, considera-se que os alimentos funcionais contribuam para o auxílio e homeostase do corpo humano (ANVISA, 2016).

Assim, acredita-se que quando um indivíduo diabético ingere alimentos funcionais, como as fibras dietéticas, encontradas em frutas, leguminosas e cereais, tais alimentos produzam vários efeitos fisiológicos no organismo, dentre eles o controle da glicemia (MIRANDA et al., 2014).

Baseado nesses fatos torna-se extremamente importante entender os benefícios dos alimentos funcionais em indivíduos com DM, e seus mecanismos de ação. Portanto justifica-se esse trabalho afim de, por meio do levantamento bibliográfico sobre os alimentos funcionais voltados ao tratamento do DM, conscientizar e auxiliar no conhecimento e entendimento de todas as pessoas que estão de forma direta ou indireta relacionadas com a doença, a ter uma melhor compreensão sobre as maneiras mais saudáveis de alimentação e como consequência uma melhor qualidade de vida.

\section{PROBLEMA DE PESQUISA}

O DM é um problema de saúde pública que afeta indivíduos de todas as idades e classes sociais, tendo seu controle e prevenção vinculados à alimentação saudável, tratamentos insulínicos e exercícios físicos (ISER et al., 2015; BRITO et al., 2016; ANAD, 2017; VENÂNCIO; GUIMARÃES, 2017). Sabe-se que problemas relacionados à má alimentação podem acarretar diversas complicações em indivíduos diabéticos, como cansaço, indisposição, dores, hiperglicemia, ocasionando até mesmo o óbito (GUYTON; HALL, 2002; PORTH; MATFIN, 2010; PATENTE, 2017).

Assim, nota-se a necessidade do entendimento na escolha dos alimentos que serão ingeridos diariamente. Nesse contexto, os alimentos funcionais apresentam diversos benefícios fisiológicos, em todos os indivíduos, destacando-se os portadores do DM (MIRANDA et al., 2014). Contudo, tais ganhos devem ser estudados para uma melhor compreensão destes efeitos.

Baseado nestes fatos surgem alguns tópicos a serem explorados para o melhor entendimento da problemática exposta:

$\checkmark \quad$ Definição/Conceito de alimento funcional.

$\checkmark \quad$ Especificidade de um alimento funcional.

$\checkmark \quad$ Eficácia do alimento funcional

$\checkmark \quad$ Função do alimento funcional na prevenção e no tratamento do diabetes.

$\checkmark \quad$ Biologia e alimentos funcionais.

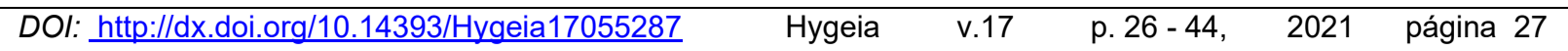




\section{OBJETIVOS}

\section{Objetivo geral}

Avaliar os benefícios dos alimentos funcionais no controle e tratamento do Diabetes Mellitus (DM).

\section{Objetivos Especificos}

No que se refere o Diabetes Mellitus e os alimentos funcionais objetiva-se:

$\checkmark \quad$ Entender o funcionamento fisiológico do pâncreas e a fisiopatologia do Diabetes Mellitus.

$\checkmark \quad$ Compreender o que são alimentos funcionais.

$\checkmark \quad$ Entender o funcionamento dos alimentos funcionais e seu papel no organismo de uma pessoa diabética. funcionais.

Destacar a importância e atuação do Biólogo nas áreas de pesquisa vinculadas aos alimentos

\section{MÉTODOS}

Trata-se de uma revisão de literatura, descritiva e discursiva, de maneira que conscientize e auxilie o leitor no conhecimento e entendimento dos alimentos funcionais por meio da leitura do artigo.

A revisão consistiu de um levantamento bibliográfico embasado em diferentes dados, como artigos, livros, revistas, cadernos de graduação, jornais, resoluções, portaria e arquivos provenientes como, por exemplo, da ANVISA, ANAD, Revista da Associação Médica Brasileira, Jornal UNESP, Revista de Ciências Farmacêuticas Básica e Aplicada, Resolução $n^{\circ} 2$, de 5 de março de 2002, Revista Hospital de Clínicas de Porto Alegre (HCPA), Revista da Faculdade de Medicina de Ribeirão Preto e do Hospital das Clínicas da FMRP Universidade de São Paulo, Scientia Medica, SBD, Revista da Escola de Enfermagem da USP.

As perguntas norteadoras que auxiliaram a busca na literatura foram:

- Qual a definição/conceito de alimento funcional?

- Qual a especificidade de um alimento funcional?

- Qual a eficácia do alimento funcional?

- Qual a função do alimento funcional na prevenção e no tratamento do diabetes?

- Qual a relação da Biologia com os alimentos funcionais?

Ademais, como critérios de inclusão foram adotados: artigos que respondessem as perguntas norteadoras, textos completos, em português, publicados a partir de 2010.

Já como critérios de exclusão: Textos que não responderam ou não se relacionavam com as perguntas norteadoras, textos pagos ou incompletos, publicados anteriormente a 2010, com exceção de (ANVISA), 1999; AZEVEDO, M. J. et al., 2002; BERTOLA, E.; MENEZES, H. apud D'AMBROSIO, O., 2001; D'AMBROSIO, O., 2001; FREITAS, M. C. F.; FOSS, M. C., 2003; GUYTON, A. C.; HALL, J. E., 2002; PANAGIOTAKOS et al., 2007.

A coleta de dados foi realizada utilizando as palavras chaves: "Diabetes", "Alimentos Funcionais" e "Tratamento".

Após a busca nas principais bases de dados (Scielo, Google acadêmico, Bireme), foram encontrados 100 artigos, sendo realizada a leitura dos resumos, e selecionados os que se incluíam nos critérios estabelecidos, restando o total de 69 artigos utilizados nesse trabalho.

\section{REVISÃO DE LITERATURA \\ ÍNDICES ATUAIS DO DIABETES MELLITUS}

De acordo com a Federação Internacional de Diabetes (IDF), no ano de 2014 o número de pessoas diagnosticadas com DM chegou a 387 milhões no mundo, atingindo um percentual de 8,3\% (BRITO et al., 2016). 
Nesse mesmo ano, estima-se que o DM tenha provocado 4,9 milhões de mortes no mundo sendo causador de $11 \%$ do dinheiro gasto em saúde com adultos, um valor considerado de 612 milhões de dólares. Já no Brasil, acredita-se que em 2011, 5,3\% das mortes ocorreram em virtude do DM, sendo a percentagem de mortalidade $33,7 \%$ mortes a cada 100 mil habitantes, embora tenha ocorrido uma redução de 1,7\% ao ano analisada em 2000 - 2011 (ISER et al., 2015).

Segundo dados da IDF no mundo, em 2010, existiam cerca de 285 milhões de pessoas portadoras de DM, esse número chegou a 387 milhões em 2013 (ISER et al., 2015; MAGALHÃES et al., 2015) sendo a mesma quantidade observada em 2014 (BRITO et al., 2016).

Dados referentes à América Central e à América do Sul evidenciam 24 milhões de pessoas afetadas, estima-se que aproximadamente $60 \%$ da população será portadora de diabetes em 2035 , ou seja, 38,5 milhões (ISER et al., 2015; MAGALHÂEES et al., 2015). No Brasil as estimativas são alarmantes, em 2015 eram 11,9 milhões de casos; para 2035 espera-se 19, 2 milhões de pessoas com DM, entre 35 a 74 anos (ISER et al., 2015).

\section{FISIOLOGIA DO FUNCIONAMENTO DO PÂNCREAS}

O pâncreas possui duas funções essenciais no organismo humano, a exógena e a endócrina. A exógena está relacionada com a liberação de substâncias no duodeno que auxiliarão na digestão dos alimentos. A endócrina está vinculada ao controle dos níveis de glicose no sangue (PATENTE, 2017).

Considerado um órgão heterogêneo, o pâncreas é constituído pelos ácinos e as ilhotas de Langerhans (Figura 1), dois tipos principais de tecidos. As ilhotas de Langerhans correspondem somente a $2 \%$ da massa total do pâncreas. Os ácinos são responsáveis pela secreção dos sucos digestivos no duodeno e as ilhotas de Langerhans são responsáveis pela secreção dos hormônios: insulina e glucagon, diretamente na corrente sanguínea (GUYTON; HALL, 2002; RHEINHEIMER et al., 2010; BENTO; BAPTISTA; OLIVEIRA, 2013).

Figura 1 - Anatomia de uma ilhota de Langerhans no pâncreas.

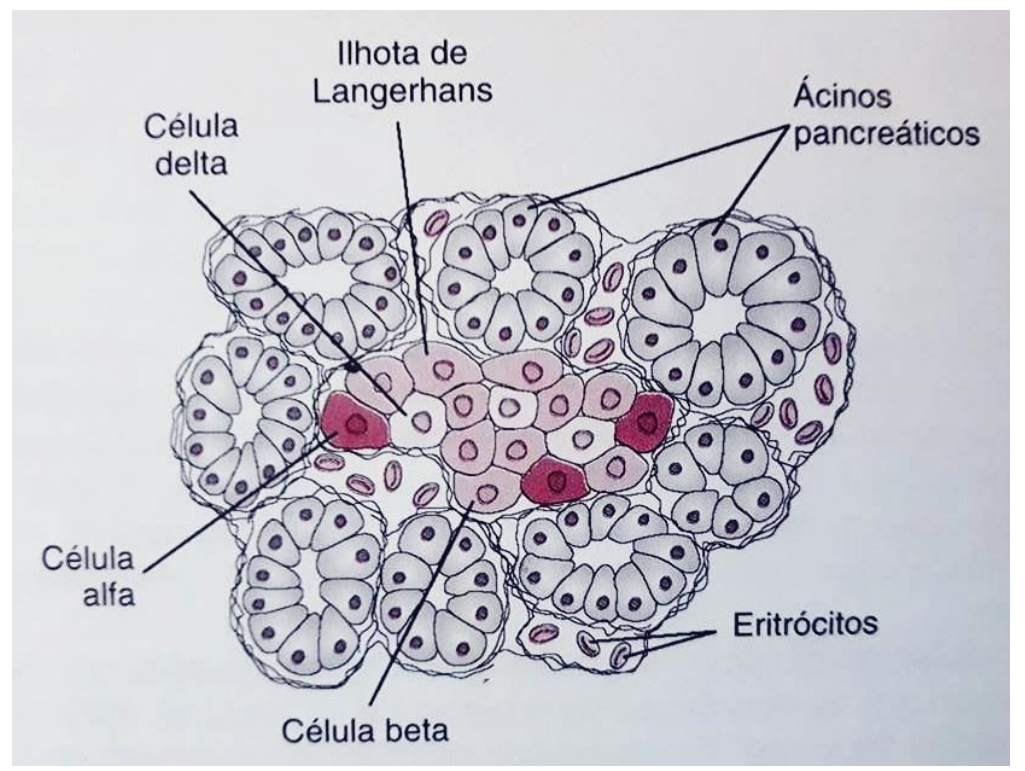

Fonte: GUYTON; HALL, 2002.

Os principais tipos de células que formam as ilhotas de Langerhans são: as células alfa (produtoras de glucagon), beta (produtoras de insulina), delta (produtoras de somatostatina) e P (produtoras de polipeptídeo prancreático) (BENTO; BAPTISTA; OLIVEIRA, 2013).

Para um bom funcionamento, o corpo precisa de quantidades controladas de glicose na corrente sanguínea, e isso ocorre em razão de dois hormônios. O primeiro é a insulina que age como um sinalizador para as células, avisando-as o momento de absorver a glicose que está em exagero na DOI: http://dx.doi.org/10.14393/Hygeia17055287 $\quad$ Hygeia $\quad$ v.17 $\quad$ p. $26-44,2021$ página 29 
corrente sanguínea. O segundo é o glucagon que tem finalidade oposta, no momento que os níveis de glicose estão baixos age como sinalizador e avisa o fígado e o tecido adiposo para que sintetizem glicose e liberem na corrente sanguínea (PATENTE, 2017).

\section{FISIOPATOLOGIA DO DIABETES MELLITUS}

Segundo a Sociedade Brasileira de Diabetes (2016), o DM não é definido como uma doença isolada, mas um conjunto heterogêneo de distúrbios metabólicos dos carboidratos, lipídios e proteínas (PORTH; MATFIN, 2010) que apresenta em comum, a deficiência nas funções da insulina, em sua ação e/ou secreção, em razão da hiperglicemia.

A fisiopatologia do DM pode basear-se na perda de funcionalidade das células beta e carência ou resistência à insulina, ou seja, os tecidos não conseguem reconhecer a existência da insulina, e isso faz com que a corrente sanguínea fique cheia de açúcar e as células fiquem sem energia (PORTH; MATFIN, 2010).

A absorção da glicose feita pelas células é considerada a principal fonte de energia para o organismo (IFSC, 2017), ocorrendo por meio da corrente sanguínea, sendo necessária para todas as atividades, como por exemplo, caminhar e correr. Em indivíduos diabéticos, quando não ocorre esse processo de forma adequada, as células ficam cansadas e sem forças para realizar as tarefas diárias, afetando a homeostase corporal (PATENTE, 2017).

O entendimento dos mecanismos relacionados ao surgimento do DM possibilitou sua classificação baseado na etiologia, e não nas formas de tratamentos, em vista disso, os termos "DM insulinodependente" e "DM insulinoindependente" não devem ser mais utilizados na classificação das categorias. A Organização Mundial da Saúde (OMS) e a Associação Americana de Diabetes (ADA) recomendam a classificação incluindo quatro classes clínicas (Figura 2): DM tipo 1 (DM1), DM tipo 2 (DM2), outros tipos específicos de DM e DM gestacional (SBD, 2016).

Figura 2 - Classificação etiológica do Diabetes Mellitus (DM).

I. Diabetes tipo 1

- destruição das células beta, usualmente levando à deficiencia completa de insulina

A. auto-imune

B. idiopático

II. Diabetes tipo 2

- graus variados de diminuição de secreçăo e resistencia à insulina

III. Outros tipos especificos
A. Defeitos genéticos da função da célula $\beta$
B. Defeitos genéticos da açâo da insulina
C. Doenças do pâncreas exơcrino
D. Endocrinopatias
E. Indução por drogas ou produtos químicos
F. Infecçōes
G. Formas incomuns de diabetes imuno-mediado

IV. Diabetes Gestacional

Fonte: AZEVEDO et al., 2002

\section{TIPOS DE DIABETES}

Existem dois tipos gerais de DM, tipo 1 e tipo 2, há ainda outros tipos específicos de DM e o DM gestacional, relacionado a categoria do diabetes do adulto (PORTH; MATFIN, 2010).

O DM tipo 1 é decorrente da ausência de secreção de insulina, ocasionada por um erro no sistema imunológico, o que não ocorre em uma pessoa não diabética (Figura 3). De modo geral, é o resultado da eliminação contínua das células beta do pâncreas, os anticorpos não as reconhecem e as atacam acreditando que sejam um agente patogênico (BRASIL, 2013, BRASIL; PONTAROLO; CORRER, 2014).

DOI: http://dx.doi.org/10.14393/Hygeia17055287 $\quad$ Hygeia $\quad$ v.17 $\quad$ p. $26-44, \quad 2021$ página 30


Em decorrência do número expressivo em crianças, adolescentes ou adultos jovens, é nomeada também como diabetes infanto-juvenil, e diabetes imunomediado, equivalendo a 5 e $10 \%$ do total de casos (SBD. 2017). No Brasil a ocorrência anual é em torno de 7,6 casos por 100.000 habitantes (BRASIL; PONTAROLO; CORRER, 2014).

Figura 3 - Curva de tolerância à glicose, em indivíduo normal e em paciente com (DM).

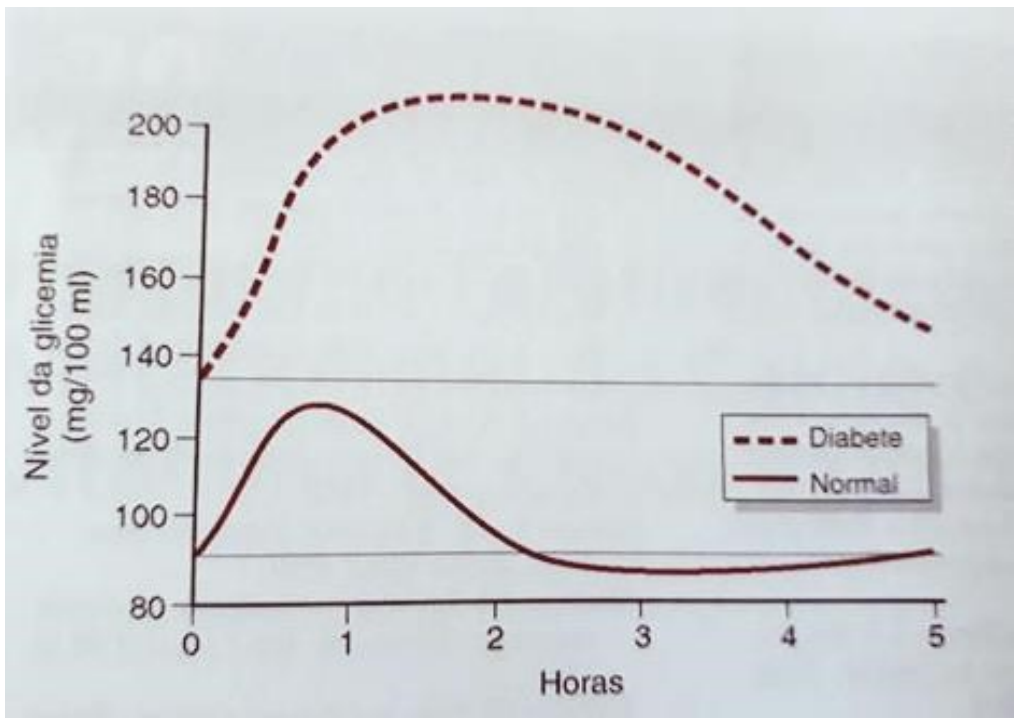

Fonte: GUYTON; HALL, 2002.

O desenvolvimento do DM tipo 1 também está relacionado com enfermidades que prejudicam a produção de insulina. Algumas implicações podem estar relacionadas com a destruição destas células como, por exemplo, o vitiligo, uma doença autoimune ou a acantose nigricans, uma infecção cutânea (RODRIGUES et al., 2010).

O DM tipo 2, também conhecido como diabetes do adulto, está vinculado a resistência à insulina (SBD, 2017), sendo decorrente da deficiência na ação da insulina existente na corrente sanguínea em cumprir de forma adequada suas funções. Assim, a resistência à insulina, ocasionada pela deficiência das células beta pancreáticas, provoca aumento das concentrações de glicose na corrente sanguínea (hiperglicemia crônica) (SANTOS et al., 2012).

Na maioria das vezes, o DM tipo 2 é notado em adultos com idade superior a 40 anos, com mais frequência entre 50-60 anos, e desenvolvendo-se de forma gradativa (GUYTON; HALL, 2002; SOUZA, 2011). Contudo, devido aos hábitos alimentares não saudáveis, ao estresse da vida urbana e sedentarismo, atualmente é muito observado em jovens (SBD, 2017; VASCONCELOS et al., 2010), e equivale a $90 \%$ dos casos (SBD, 2017).

Os outros tipos específicos de DM podem ser desenvolvidos e estão incluídos nesta categoria os defeitos genéticos na ação da insulina, como por exemplo, resistência a insulina do tipo $A$, a síndrome de Rabson-Mendenhall, ou a defeitos genéticos na função das células beta, como defeitos no gene HNF4A (MODY 1), defeitos no gene GCK (MODY 2), DM mitocondrial, também pode estar vinculado a doenças do pâncreas exócrino, como, Pancreatite, Pancreatectomia ou trauma, ou por causa de infecções como a Rubéola congênita e Citomegalovírus (SBD, 2015).

Existem também formas incomuns de DM autoimune que é o caso da Síndrome de Stiff-Man ou dos anticorpos antirreceptores de insulina. As Endocrinopatias, Acromegalia, Síndrome de Cushing e outras síndromes genéticas como a Síndrome de Down, Síndrome de Turner e a indução de agentes químicos ou medicamentos como Pendamidina, Ácido Nicotínico, Diazóxido e Glicocorticoides também fazem parte desta categoria (SBD, 2015). 
O Diabetes Mellitus Gestacional (DMG) está vinculado ao DM tipo 2, e é detectado pela primeira vez no período da gravidez, desenvolvendo-se pela intolerância à glicose, podendo continuar após o parto ou não (PORTH; MATFIN, 2010; BRASIL, 2010).

\section{FATORES DE RISCO}

Segundo a SBD (2017), os fatores de risco associados ao DM tipo 1 estão relacionados à influência genética da família, já o DM tipo 2, pode estar vinculado ao aumento do colesterol, ou alterações nos números de triglicérides sanguíneo e hábitos alimentares inadequados. Outros fatores relatados são o sedentarismo, a obesidade, o aumento da pressão arterial (VASCONCELOS et al., 2010), o envelhecimento e a hereditariedade, determinantes na predisposição da destruição das células beta (SANTOS et al., 2012).

Acredita-se que pessoas com apneia do sono, dislipidemia ou que apresentem algum tipo de disfunção psiquiátrica, como transtorno bipolar, depressão, esquizofrenia e até mesmo mulheres com a síndrome de ovários policísticos, além de usuários de determinados medicamentos como, por exemplo, os glicocorticoides, também tenham predisposição ao desenvolvimento da doença (TOLEDO, 2016; SBD, 2017).

Em algumas situações, recém-nascidos podem apresentar peso maior do que quatro quilos, o que pode também ser considerado fator de risco. Além disso, sabe - se que, se a mãe apresentou diabetes durante a gravidez, a mesma produziu quantidades maiores de insulina para que os níveis glicêmicos ficassem ajustados, e esta insulina, pode agir diretamente no bebê, provocando o aumento dos órgãos e consequentemente o sobrepeso, esse processo é denominado macrossomia fetal (RENCK, 2015).

\section{COMPLICAÇÕES}

O DM destaca-se por interferir de maneira ativa no aumento na incidência de doenças e mortes no mundo em decorrência de suas complicações agudas e crônicas (REGULA SUS, 2015).

As circunstâncias crônicas estão relacionadas à nefropatia, neuropatia e retinopatia (TSCHIEDEL, 2014), as circunstâncias agudas mais notáveis são a hipoglicemia grave e a cetoacidose diabética (CAD). Estas podem provocar modificações nos graus de consciência do indivíduo com implicações de vias aéreas, podendo levar ao coma ou até mesmo à morte (OLIVEIRA et al., 2014).

Além disso, as altas concentrações de glicose liberadas na urina provocam um processo denominado diurese osmótica, que é causada pela (CAD) (PIRES, 2014).

Alguns dos sintomas da (CAD) são: desidratação intracelular e extracelular, perda acelerada de peso, hálito cetônico, a poliúria (eliminação de urina em excesso) e a polidipsia (vontade exagerada de beber água). Estes dois últimos, são conhecidos como as manifestações clinicas mais frequentes do DM (PIRES, 2014). Por conseguinte, sabe-se que se o indivíduo não fizer os tratamentos adequados, poderá perder muito dos tecidos corporais, ocorrendo o óbito em poucas semanas (GUYTON; HALL, 2002).

A hiperglicemia, decorrente tanto da redução do uso periférico de glicose como do acréscimo de sua produção endógena (glicogenólise e neoglicogênese), é um constituinte fisiopatológico característico da situação, esclarecendo vários sintomas e sinais típicos da CAD, como poliúria, polidipsia e graus diversificados de desidratação, que podem alcançar à hipovolemia acentuada e choque circulatório (FREITAS; FOSS, 2003).

Com o passar do tempo os vasos sanguíneos de variados tecidos podem funcionar de maneira anormal quando a glicemia não é controlada de forma correta, apresentando modificações nas estruturas, ocasionando consequentemente um fornecimento desapropriado de sangue para os tecidos (GUYTON; HALL, 2002; PALAZZIN et al., 2012).

Estes problemas possibilitam o desenvolvimento de ataque cardíaco, acidente vascular encefálico, doença vascular periférica, estágio terminal de doença renal, retinopatia, cegueira, isquemia, e gangrena dos membros (SOUZA et al., 2012). 


\section{Diagnóstico}

As diretrizes da SBD (2015) informam que os principais sintomas do diabetes são: poliúria, polidipsia, polifagia (comer de forma excessiva) e perda espontânea de peso.

Os exames laboratoriais realizados para o diagnóstico de diabetes e de regulação da glicemia alterada (Figura 4) são (SBD, 2015):

Figura 4 - Valores de glicose plasmática (em $\mathrm{mg} / \mathrm{dl})$ para diagnóstico de DM e seus estágios préclínicos.

\begin{tabular}{|l|l|l|l|}
\hline \multicolumn{1}{|c|}{ CATEGORIA } & \multicolumn{1}{|c|}{ JEJUM* } & $\begin{array}{c}2 \text { H APOS 75 G } \\
\text { DE GLICOSE }\end{array}$ & \multicolumn{1}{c|}{ CASUAL** $^{* *}$} \\
\hline Glicemia normal & $<100$ & $<140$ & \\
\hline $\begin{array}{l}\text { Tolerância à glicose } \\
\text { diminuida }\end{array}$ & $>100 \mathrm{a}<126$ & $\geq 140 \mathrm{a}<200$ & $\begin{array}{l}\geq 200 \text { (com sintomas } \\
\text { clássicos)*** }\end{array}$ \\
\hline Diabetes mellitus & $\geq 126$ & $\geq 200$ & \\
\hline
\end{tabular}

Fonte: DIRETRIZES SBD, 2015.

Glicemia de jejum: o nível de glicose sanguínea deve ser observado depois de um jejum de 8 a 12 horas;

Teste oral de tolerância à glicose (TTG-75g): o paciente em jejum recebe uma quantidade de $75 \mathrm{~g}$ de glicose e a glicemia é observada antes e 120 minutos depois de ingerida;

Glicemia casual: é a glicemia sem padronização de tempo desde a última refeição feita pelo paciente.

Assim, depois de constatada, os cuidados relacionados ao DM devem estar inteiramente relacionados ao tratamento medicamentoso, dietas e mudanças no estilo de vida do indivíduo (ANAD, 2017).

\section{TRATAMENTO}

O tratamento medicamentoso para o DM tipo 1 é feito por meio do uso da insulina desde o diagnóstico, pois as células beta param de cumprir sua função no organismo. Para o diabetes tipo 2 utiliza-se medicamentos via oral, caso o controle não seja conquistado por meio destes, o uso da insulina é necessário para que os níveis glicêmicos fiquem controlados (ANAD, 2017).

A atividade física também é essencial no tratamento de pessoas diabéticas, tendo eficiência confirmada na melhoria do peso corporal, da capacidade funcional, e no controle dos níveis de glicemia (VENÂNCIO; GUIMARÃES, 2017), melhoramento a absorção da glicose pelos músculos, diminuindo assim, a quantidade de insulina utilizada, prevenindo complicações nos nervos, rins, vasos sanguíneos, coração e alterações na retina (GONÇALVES et al., 2016).

Os exercícios físicos devem estar agregados a uma boa alimentação, baseada em uma dieta que auxilie na redução da glicemia, evitando assim o agravo da doença. O portador de DM deve ser orientado de que, toda vez que for iniciada uma atividade física é necessário atenção especial com a alimentação, esta deve ser rica no consumo de fibras, frutas e líquidos (VENÂNCIO; GUIMARÃES, 2017).

Vinculado a esses fatos, a European Association for the Study of Diabetes e a American Diabetes Association (EASD; ADA, 2013) preconizam como critério relacionado à dieta de indivíduos diabéticos a diminuição do teor energético, bem como do teor de gordura saturada e aumento da ingestão de fibra.

Destacando-se como principais tipos de dieta:

- Dieta rica em proteína: favorece que o indivíduo perca peso por ser classificada termogênica, sacietógena e por conservar a massa magra de maneira preferencial à massa gorda durante a perda 
de peso. Tem o consumo calórico total de $>25 \%$ e traz benefícios para a glicemia pós-prandial quando comparada a dietas abundantes em carboidratos (EASD; ADA, 2013).

- Dieta rica em gordura e baixíssimo carboidrato: a dieta do Atkins é um exemplo, e, que a diminuição da ingestão de carboidratos para uma quantidade inferior a $20 \mathrm{~g}$ diária provoca cetose, o que induziria a utilização de gordura como fonte de energia preferencial, e não a glicose. Ela é benéfica para o controle da glicemia, pois reduz os acúmulos de glicose e insulina (EASD; ADA, 2013).

- Dieta do mediterrâneo: ocorre à substituição da carne vermelha pela carne branca, como a carne do frango e do peixe na maioria das refeições, inclui também legumes em grande quantidade, nozes, frutas, óleo de oliva, grãos e vinho de forma moderada. É benéfica na diminuição das glicemias pósprandiais e dos níveis de hemoglobina glicada (EASD; ADA, 2013).

Além dos diversos tipos de dietas, pesquisas atuais demonstram que os alimentos funcionais fornecem as necessidades diárias de proteínas, vitaminas, carboidratos e minerais, sendo compostos por substâncias bioativas que auxiliam na prevenção de diversas doenças, sendo uma delas, o diabetes. Assim, por meio destes compostos bioativos é possível melhorar o sistema imunológico e o metabolismo, promovendo desta forma, saúde física e mental, atuando diretamente no fortalecimento do organismo (SULZBACH et al., 2012).

Deste modo, sabe-se que os alimentos funcionais têm grande impacto na dieta, e, portanto, no tratamento e prevenção do DM, desempenhando funções benéficas no organismo de uma pessoa diabética (SULZBACH et al., 2012).

\section{ALIMENTOS FUNCIONAIS}

A expressão "alimentos funcionais" surgiu pela primeira vez nos anos de 1980 no Japão. A preocupação do governo japonês com as pessoas da terceira idade aumentou devido ao acréscimo de casos de doenças não transmissíveis. Esta problemática fez com que a indústria alimentícia, por meio de uma solicitação feita pelo governo, providenciasse alguma resposta que ajudasse a população japonesa na época. A partir disso surgiram diversos alimentos reforçados em minerais, vitaminas, e atualmente, estes alimentos podem incluir ainda, ácidos graxos, proteínas, bactérias, carotenoides, fibras e diversos componentes (SANTOS, 2011).

Os alimentos funcionais também são denominados como nutracêuticos, fármaco-nutrientes e integradores dietéticos (NITZKE, 2012). Estudos realizados em animais e seres humanos demonstram que alguns destes alimentos têm papel importante no metabolismo e na regulação fisiológica do organismo, estimulando a saúde e a nutrição, agindo de forma a prevenir o desenvolvimento de doenças, além disso, seus componentes podem reduzir o risco de adquirir determinadas doenças (SANTOS, 2011).

Outros estudos buscam desvendar prováveis propriedades funcionais de diversos alimentos para a prevenção e o tratamento de muitas doenças, como câncer, doenças cerebrais, aterosclerose e, em destaque neste trabalho, o DM (FRANÇA et al., 2010).

Sabe-se que para ser considerado um alimento funcional é necessário apresentar compostos específicos na composição, podendo estes ser ou não nutrientes (SANTOS, 2011). Assim, as condições necessárias para que um ou mais alimentos sejam classificados como funcionais podem ser (PERIN; ZANARDO, 2015):

"Um alimento natural; um alimento ao qual um componente foi adicionado; um alimento do qual um componente foi removido; um alimento no qual a natureza de um ou mais componentes foi modificada; um alimento no qual a biodisponibilidade de um ou mais componentes foi modificada".

No Brasil, o Ministério da Saúde, regulamentou os Alimentos Funcionais por meio da ANVISA (1999) como:

"O alimento ou ingrediente que alegar propriedades funcionais ou de saúde pode, além de funções nutricionais básicas, quando se tratar de nutriente, produzir efeitos metabólicos e ou fisiológicos e ou efeitos benéficos à saúde, devendo ser seguro para consumo sem supervisão médica".

Além disso, o Ministério da Saúde apresenta os compostos funcionais essenciais dos alimentos, destacando sua utilização e o local em que são encontrados, como descritos na Tabela 1 (PFIZER, 2014).

DOI: http://dx.doi.org/10.14393/Hygeia17055287 $\quad$ Hygeia $\quad$ v.17 $\quad$ p. 26-44, 2021 página 34


Tabela 1 - Compostos funcionais, ação no organismo e alimentos funcionais.

\begin{tabular}{|c|c|c|}
\hline Compostos funcionais & Ação no organismo & Alimentos Funcionais \\
\hline Ácido a - linolênico & $\begin{array}{c}\text { Ação antiflamatória e impulsiona } \\
\text { o sistema imunológico. }\end{array}$ & $\begin{array}{l}\text { Soja, amêndoas, nozes, colza, e } \\
\text { óleos de linhaça. }\end{array}$ \\
\hline Ácidos graxos / ômega - 3 & $\begin{array}{l}\text { Reduz o colesterol LDL, tem ação } \\
\text { anti-inflamatória que é } \\
\text { fundamental para o } \\
\text { desenvolvimento da retina de } \\
\text { recém-nascidos e do cérebro. }\end{array}$ & $\begin{array}{c}\text { Peixes marinhos como o salmão, } \\
\text { anchova, atum, arenque, sardinha, } \\
\text { etc. }\end{array}$ \\
\hline Catequinas & $\begin{array}{c}\text { Diminuem a ocorrência de } \\
\text { colesterol, alguns tipos de câncer } \\
\text { e impulsionam o sistema } \\
\text { imunolóqico. }\end{array}$ & $\begin{array}{l}\text { Framboesas, vinho tinto, uva roxa, } \\
\text { mirtilo, chá verde, amoras e cereja. }\end{array}$ \\
\hline Estanóis e esteróis vegetais & $\begin{array}{c}\text { Diminuem a chance de doenças } \\
\text { cardiovasculares. }\end{array}$ & $\begin{array}{l}\text { Extraídos de óleos vegetais como } \\
\text { madeiras e de soja. }\end{array}$ \\
\hline Fibras solúveis e insolúveis & $\begin{array}{l}\text { Auxiliam na melhoria do } \\
\text { funcionamento intestinal e na } \\
\text { redução de câncer de cólon. } \\
\text { As solúveis concedem maior } \\
\text { saciedade e em razão disto } \\
\text { podem auxiliar no controle da } \\
\text { glicemia e no tratamento da } \\
\text { obesidade. }\end{array}$ & $\begin{array}{l}\text { Leguminosas como ervilha, feijão, } \\
\text { soja, etc; cereais integrais como } \\
\text { centeio, farelo de trigo, aveia, cevada, } \\
\text { etc; frutas com casca e hortaliças com } \\
\text { talos. }\end{array}$ \\
\hline Flavonóides & $\begin{array}{c}\text { Desempenham função } \\
\text { antioxidante, anticancerígena, } \\
\text { anti-inflamatória, vasodilatadora. }\end{array}$ & $\begin{array}{l}\text { Alcachofra, frutas cítricas, tomate, } \\
\text { cereja, soja e pimentão. }\end{array}$ \\
\hline Indóis e Isotiocianatos & $\begin{array}{c}\text { Induzem as enzimas protetoras } \\
\text { contra o câncer, especialmente o } \\
\text { de mama. }\end{array}$ & $\begin{array}{l}\text { Repolho, couve de bruxelas, couve } \\
\text { flor, brócolis, mostarda, rabanete. }\end{array}$ \\
\hline Isoflavonas & $\begin{array}{l}\text { Desempenha ação } \\
\text { anticancerígena e estrogênica, ou } \\
\text { seja, auxilia na redução de } \\
\text { sintomas da menopausa. }\end{array}$ & Soja e derivados. \\
\hline Licopeno & $\begin{array}{l}\text { Abaixa o colesterol e a } \\
\text { probabilidade de alguns tipos de } \\
\text { câncer, como por exemplo, o de } \\
\text { próstata e possui também ação } \\
\text { antioxidante. }\end{array}$ & $\begin{array}{l}\text { Frutas vermelhas como o pimentão } \\
\text { vermelho, tomate e derivados, a } \\
\text { melancia e a goiaba vermelha. }\end{array}$ \\
\hline Lignanas & $\begin{array}{l}\text { Estes compostos atuam como } \\
\text { inibidores de tumores hormônio- } \\
\text { dependentes. }\end{array}$ & Linhaça e noz moscada. \\
\hline Luteína e Zeaxantina & $\begin{array}{l}\text { Defende contra a degeneração } \\
\text { macular e tem ação antioxidante. }\end{array}$ & $\begin{array}{c}\text { Pequi e milho (zeaxantina) e folhas } \\
\text { verdes (luteína). }\end{array}$ \\
\hline $\begin{array}{c}\text { Prebióticos: } \\
\text { Frutooligossacarídeos, Inulina }\end{array}$ & $\begin{array}{c}\text { Favorecem o bom funcionamento } \\
\text { do intestino devido à ativação da } \\
\text { microflora intestinal. }\end{array}$ & $\begin{array}{c}\text { Extraídos de vegetais como raiz de } \\
\text { batata yacon e chicória. }\end{array}$ \\
\hline $\begin{array}{c}\text { Probióticos: } \\
\text { Bífidobacterias e Lactobacilos }\end{array}$ & $\begin{array}{c}\text { Reduzem a chance de câncer de } \\
\text { cólon e constipação e beneficiam } \\
\text { as funções gastrointestinais. }\end{array}$ & $\begin{array}{l}\text { Produtos lácteos fermentados como } \\
\text { logurtes e Leites. }\end{array}$ \\
\hline Proteínas de soja & $\begin{array}{l}\text { Auxilia na diminuição dos níveis } \\
\text { de colesterol. }\end{array}$ & Soja e derivados. \\
\hline $\begin{array}{l}\text { Sulfetos alílicos: } \\
\text { Alilsulfetos }\end{array}$ & $\begin{array}{c}\text { Beneficiam o sistema } \\
\text { imunológico e restringem o risco } \\
\text { de câncer gástrico, pressão } \\
\text { sanguínea e colesterol. }\end{array}$ & Alho e na cebola. \\
\hline Tanino & $\begin{array}{l}\text { Desempenha as funções: anti- } \\
\text { séptico, vaso-condutor e } \\
\text { antioxidante. }\end{array}$ & $\begin{array}{c}\text { Alimentos como sorgo, maçã, sálvia, } \\
\text { manjericão, caju, manjerona, soja e } \\
\text { uva. }\end{array}$ \\
\hline
\end{tabular}

Fonte: PFIZER, 2014. Adaptado. 
Outros alimentos de destaque são os lipídios, da classe dos terpenos e o ácido ascórbico, encontrados na vitamina $C$, nas frutas cítricas, evidenciam-se também os tocotrienóis, presente na vitamina $E$ de grãos de cereais e vegetais, os isoflavonóides da soja, o licopeno do tomate, melancia e goiaba, os polifenólicos do gengibre e dos chás preto e verde, o resveratrol das cascas das uvas, as antocianinas da cereja, uva, amora, morango e feijão, a quercetina nos brócolis, na cebola, maçã, cereja, uva vermelha (vinho), e alguns cereais e também a função antioxidante da sálvia, do orégano, do tomilho e do alecrim (FRANÇA et al., 2010).

Além disso, acredita-se que exista relação entre alimentos funcionais e sistema imunológico. Esta é destacada pelos mecanismos de ação dos compostos funcionais no organismo de uma pessoa (FRANÇA et al, 2010).

\section{A RELEVÂNCIA DOS ALIMENTOS FUNCIONAIS NA PREVENÇÃO E NO TRATAMENTO DO DIABETES}

Os compostos bioativos, também chamados de componentes químicos e compostos funcionais, presentes nos alimentos funcionais, agem de maneira a prevenir e tratar o diabetes e são encontrados em diversos alimentos (VIDAL, 2012; PFIZER, 2014; CARVALHO; PERUCHA, 2015).

Assim, os diabéticos ou pessoas que possuem influência para desenvolvê-la se beneficiam com os efeitos positivos provocados por estes compostos no organismo, auxiliando consequentemente na prevenção e no tratamento da doença. Alguns dos alimentos funcionais que executam estas funções são (Tabela 2): Aveia, Oleaginosas, Probióticos, Gorduras poli-insaturadas (Ômega 3) e Soja (CARVALHO; PERUCHA, 2015).

Tabela 2 - Alimentos funcionais, compostos bioativos, quantidade recomendada e efeitos no organismo.

\begin{tabular}{|l|l|l|l|}
\hline \multicolumn{1}{|c|}{$\begin{array}{c}\text { Alimentos } \\
\text { funcionais }\end{array}$} & \multicolumn{1}{|c|}{ Compostos Bioativos } & \multicolumn{1}{c|}{$\begin{array}{c}\text { Quantidade } \\
\text { recomendada }\end{array}$} & Efeitos no organismo \\
\hline Aveia & B-glucana. & $40 \mathrm{~g} /$ dia & $\begin{array}{l}\text { Diabete: reduz a absorção } \\
\text { da glicose. }\end{array}$ \\
\hline Oleaginosas & $\begin{array}{l}\text { Resveratrol, SG monoinsaturados e } \\
\text { vitamina E. }\end{array}$ & $30-60 \mathrm{~g} /$ dia & $\begin{array}{l}\text { Diabete: reduz a resistência } \\
\text { à insulina. }\end{array}$ \\
\hline Probióticos & $\begin{array}{l}\text { Microrganismos que atuam na } \\
\text { microbiota intestinal. }\end{array}$ & $\begin{array}{l}1-2 \text { bilhões de } \\
\text { unidade } \\
\text { formadoras } \\
\text { colônia/dia }\end{array}$ & $\begin{array}{l}\text { Diabete: reduz a destruição } \\
\text { das células beta do } \\
\text { pâncreas. }\end{array}$ \\
\hline $\begin{array}{l}\text { Gorduras } \\
\text { poliinsaturadas } \\
\text { (Ômega 3) }\end{array}$ & $\begin{array}{l}\text { Peixes: salmão, atum, arenque. } \\
\text { Linhaça dourada: usar com cautela } \\
\text { pois o w3 inibe a agregação } \\
\text { plaquetária e o paciente apresenta } \\
\text { baixa coagulação sanguínea pela } \\
\text { suplementação mal orientada. }\end{array}$ & $0,5-1,8 \mathrm{~g}$ EPA+DHA & $\begin{array}{l}\text { Diabete: diminui } \\
\text { resistência à insulina. }\end{array}$ \\
\hline Soja & $\begin{array}{l}\text { Isoflavonas (daidzeína, gliciteína, } \\
\text { genisteína), Saponinas, Lecitinas, } \\
\text { Proteínas. }\end{array}$ & $25 \mathrm{~g}$ de proteína/dia & $\begin{array}{l}\text { Diminui a resistência à à } \\
\text { insulina, contribuindo na } \\
\text { manutenção da glicemia. }\end{array}$ \\
\hline
\end{tabular}

Fonte: CARVALHO; PERUCHA, 2015. Adaptado.

O composto bioativo isoflavona, encontrado na soja, tem conquistado espaço nas pesquisas científicas em razão de seu desempenho antidiabético. Estudos em ratos com DM tipo 2 demonstram que os compostos bioativos isoflavona e a genisteína da soja apresentam capacidade estimuladora de proliferação de células beta pancreáticas, dessa forma, incentivam a secreção da insulina. Além disto, a genisteína também estimula a inibição das dissacaridases intestinais, diminuindo a presença de glicose na corrente sanguínea (SALGADO, 2017).

Assim, como mencionado na Tabela 2, os compostos bioativos apresentam vários efeitos benéficos no organismo de uma pessoa diabética, como a redução da absorção da glicose, redução da

DOI: http://dx.doi.org/10.14393/Hygeia17055287 $\quad$ Hygeia $\quad$ v.17 $\quad$ p. 26-44, 2021 página 36


resistencia à insulina e diminuição da destruição das células beta do pâncreas. Estes efeitos positivos contribuem para a manutenção da glicemia, sendo gerados a partir dos compostos funcionais encontrados nos alimentos funcionais (CARVALHO E PERUCHA, 2015).

Portanto, as recomendações para a dieta alimentar de um diabético estão vinculadas à restrição dos açúcares e obtenção de um cardápio rico em vitaminas e minerais, incluindo o consumo de duas a quatro porções de frutas diariamente, sendo uma delas rica em Vitamina $C$, e três a cinco porções de hortaliças. Além disso, é necessário priorizar alimentos ricos em fibras, como o Beta-D-glucanas, já que estes são responsáveis pelo retardo da absorção de glicose na corrente sanguínea, proporcionando o controle da glicemia (VIDAL, 2012; MUNHOZ, 2014).

A relevância das fibras na dieta dos diabéticos é muito grande (VIDAL, 2012; MUNHOZ, 2014; CAMARGO, 2017), em razão disto, deve-se destacar os alimentos com maiores teores de fibras (Tabela 3), para o consumo por indivíduos diabéticos (COSTA, 2014).

Outros alimentos ricos em fibras e amidos resistentes também retardam a absorção da glicose na corrente sanguínea e evitam o descontrole da glicemia, como por exemplo, a casca de maracujá, a batata yacon e a banana verde (CAMARGO, 2017).

Estudos apontam que a casca do maracujá é rica em vitamina B3, ferro, cálcio e fósforo, sendo muito eficaz no controle do DM, pois age diretamente na redução da glicemia. Acredita-se que seja também rica em fibras solúveis, especialmente a pectina, que age de maneira benéfica no organismo e, por isso, auxilia na prevenção do DM. O extrato seco da casca de maracujá amarelo desempenha função positiva no controle glicêmico de indivíduos com DM tipo 2, em razão da pectina ser totalmente degradada no organismo, o que ocasiona a diminuição da taxa de glicose na corrente sanguínea (ZERAIK et al., 2010).

Alguns peixes como o salmão, atum, sardinha, bacalhau e arenque também são alvos de estudo nos alimentos funcionais, devido aos benefícios medicinais e nutricionais que proporcionam ao organismo humano, por apresentarem ômega-3 e ácidos graxos em sua composição (BASHO; BIN, 2010).

Panagiotakos et al. (2007) realizaram estudo nas Ilhas Mediterrâneas, analisando os hábitos alimentares de pessoas com idade superior a 65 anos por um ano, por meio de questionário de frequência alimentar semi-quantitativa. Foi observado que $90 \%$ das pessoas estudadas comiam peixes pelo menos há trinta anos e no mínimo uma vez por semana, e retrataram chance $14 \%$ menor de adquirir DM.

Outros alimentos funcionais apresentam ações benéficas no organismo de indivíduos diabéticos. A Tabela 3 demonstra os benefícios de diversos deles, como: a linhaça, que tem efeito favorável na redução da glicemia e melhora à tolerância da glicose; a farinha de casca de maracujá, que auxilia na prevenção e controle de doenças; a cebola e o alho, que contribuem no tratamento e na prevenção do diabetes e diminuem os níveis elevados de glicose na corrente sanguínea (ZAPAROLLI et al., 2013).

Estudos em ratos com DM tipo 2, demonstraram ainda, que o consumo de alho negro envelhecido ocasiona melhora da resistência à insulina. Este alimento possui como compostos funcionais os aminoácidos que desempenham o efeito antioxidante, diante disto, propõe-se que a sua ingestão possa ter utilidade na prevenção de complicações consequentes do DM (MACHADO; MALDONADE, 2016).

A Embrapa Hortaliças e a Universidade de Brasília (UNB, 2014) conduziram um projeto de pesquisa que avaliou a eficiência da abóbora Gila na prevenção do DM tipo 2. O estudo evidenciou ação antihipergliceminante (quando a substância de um alimento coopera para a diminuição dos níveis de glicose no sangue), assim, a espécie Gila exibiu maior quantidade de substâncias cucurbitáceas, responsáveis pela ação anti-hipergliceminante.

Acredita-se que a semente, a casca e a polpa também tenham compostos funcionais sulfonilureias, responsáveis por estimular a secreção de insulina pelas células do pâncreas (EMBRAPA, 2014).

Já os cogumelos são alimentos funcionais com baixa quantidade de gordura, ricos em carboidratos e vitaminas, e contêm taxa de proteínas aproximadamente semelhante à da carne e mais que algumas frutas e vegetais. Possuem vários compostos funcionais, sendo um deles, os peptidoglicanos, responsável pelo efeito de hipoglicemia no organismo (DINIZ, 2014).

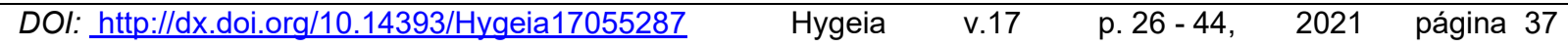


Tabela 3 - Alimentos funcionais, componentes químicos e efeitos no organismo.

\begin{tabular}{|c|c|c|}
\hline Alimentos funcionais & Componentes químicos & Efeitos no organismo \\
\hline Linhaça & Ácidos graxos; ômega 3 & $\begin{array}{l}\text { Redução da glicemia e melhora à } \\
\text { tolerância da glicose. }\end{array}$ \\
\hline Farinha de casca de maracujá & $\begin{array}{l}\text { Fibra do tipo solúvel (pectinas e } \\
\text { mucilagens) }\end{array}$ & $\begin{array}{l}\text { Auxilia na prevenção e controle de } \\
\text { doenças. }\end{array}$ \\
\hline Cebola & Fitoquímicos; flavonóide quercetina & $\begin{array}{l}\text { Tratamento e prevenção de várias } \\
\text { doenças, incluindo o diabetes; } \\
\text { antioxidante. }\end{array}$ \\
\hline Alho & Fitoquímicos; selênio; aliina & $\begin{array}{l}\text { Tratamento e prevenção de várias } \\
\text { doenças, incluindo o diabetes; } \\
\text { antioxidante; ação hipotensora e } \\
\text { hipoglicemiante. }\end{array}$ \\
\hline Alho negro envelhecido & Aminoácidos & $\begin{array}{l}\text { Prevenção de complicações } \\
\text { consequentes do diabetes. }\end{array}$ \\
\hline Abóbora Gila & Cucurbitáceas & Ação anti-hipergliceminante. \\
\hline $\begin{array}{l}\text { Abóbora Gila: semente, casca e } \\
\text { polpa }\end{array}$ & Sulfonilureias & $\begin{array}{l}\text { Estimula a secreção de insulina } \\
\text { desde as células do pâncreas. }\end{array}$ \\
\hline Bebida de yacon e caju & Fruto-oligossacarídeos (FOS) & $\begin{array}{l}\text { Aumento da ação antioxidante e dos } \\
\text { microrganismos benéficos da flora } \\
\text { intestinal. } \\
\text { Diminuição da glicemia. }\end{array}$ \\
\hline Cogumelos & Peptidoglicanas & Efeito de hipoglicemia. \\
\hline Quiabo & Moléculas polifenólicas & Redução da glicemia. \\
\hline
\end{tabular}

Fonte: ZAPAROLLI et al., 2013; EMBRAPA; (UNB), 2014; MOURA, 2014; DINIZ, 2014; MACHADO; MALDONADE, 2016; ANAD, 2017. Adaptado.

O quiabo também auxilia no controle do diabetes, visto que apresenta em sua composição, moléculas polifenólicas, responsáveis pela redução de glicose na corrente sanguínea (ANAD, 2017).

Outro experimento realizado pela Universidade Federal de Alfenas (UNIFAL-MG) utilizando uma bebida a base de yacon, um fruto-oligossacarídeos (FOS), e caju. A bebida foi testada em animais diabéticos, constatando-se que o sistema antioxidante e os microrganismos benéficos da flora intestinal aumentaram, e consequentemente, os índices glicêmicos diminuíram. Estes resultados assemelharam-se estatisticamente aos índices dos animais não diabéticos, contudo evidenciou-se que mesmo com tal diminuição glicêmica os mesmos permaneceram diabéticos (MOURA, 2014).

Assim, sabe-se que pesquisas vinculadas aos alimentos funcionais são importantíssimas, pois estão diretamente relacionadas à prevenção e o controle de muitas doenças, incluindo o DM, e é por meio delas que se torna possível descobrir os reais benefícios desses compostos funcionais para a saúde (SULZBACH et al., 2012; ZAPAROLLI et al., 2013). Contudo, ainda são necessários muitos estudos, já que diversos alimentos ainda não apresentam seus efeitos confirmados cientificamente (PERIN; ZANARDO, 2015).

Vinculado a estes fatos, o Conselho Federal de Biologia (CFBio, 2010) destaca a relevância do treinamento e do ensino na área de saúde deste profissional, que, por conseguinte, pode colaborar na qualidade de vida da humanidade e no desenvolvimento da ciência.

\section{BIOLOGIA E ALIMENTOS FUNCIONAIS}

A Resolução $n^{\circ}$ 227/2010, de 18 de agosto de 2010, decreta a respeito da regulamentação das atividades profissionais e de atuação do Biólogo em diversas áreas incluindo a saúde. Assim, foram estabelecidas as atividades que o profissional pode exercer no campo da pesquisa, o que contribui para o desenvolvimento da ciência como um todo (CFBio, 2010).

Algumas destas atividades definidas pelo (CFBio, 2010) são:

$$
\begin{aligned}
& \checkmark \text { Análises Citogenéticas. } \\
& \checkmark \text { Análises Citopatológicas. }
\end{aligned}
$$




\title{
$\checkmark$ Análises Clínicas. \\ $\checkmark$ Análises e Diagnósticos Biomoleculares. \\ $\checkmark$ Treinamento e Ensino na Área de Saúde.
}

O (CFBio, 2014) ainda, expressa no artigo 4 do Código de Ética do Biólogo sobre a melhoria da qualidade de vida em todas suas formas e manifestações:

\begin{abstract}
"Art. $4^{\circ}$ - O Biólogo terá como princípio orientador no desempenho das suas atividades o compromisso permanente com a geração, a aplicação, a transferência, a divulgação e o aprimoramento de seus conhecimentos e experiência profissional sobre Ciências Biológicas, visando o desenvolvimento da Ciência, a defesa do bem comum, a proteção do meio ambiente e a melhoria da qualidade de vida em todas suas formas e manifestações".
\end{abstract}

Portanto, a divulgação e o aprimoramento de seus conhecimentos são alguns dos princípios orientadores no desempenho das suas atividades, e todos estes devem visar o desenvolvimento da ciência (CFBio, 2014).

Baseado nessas determinantes, o biólogo Hércules Menezes, do Instituto de Biociências, campus de Rio Claro e a nutricionista Eveline Bertola chefe do Hospital Santa Filomena, também em Rio Claro são autores do livro Guia Culinário com Alimentos Funcionais: 101 receitas preventivas e terapêuticas. Na obra são apresentadas 101 receitas preventivas e terapêuticas para a saúde, com detalhadas referências científicas sobre alimentação saudável (D’AMBROSIO, 2001).

Menezes e Bertola apud D'ambrosio (2001) afirmam que a ingestão de alimentos funcionais associados a um estilo de vida saudável reduz a probabilidade de desenvolver inúmeras doenças, além de ajudar no tratamento e na cura da maior parte delas. Por isso, é importante ressaltar que a alimentação correta e práticas de vida saudáveis são fundamentais.

Portanto, destaca-se a importância do biólogo, sendo este profissional fundamental para o andamento das pesquisas com alimentos funcionais. Vinculado a estes fatos o Conselho Regional de Biologia da $4^{a}$ Região (CRBio-04, 2016) dos estados de Minas Gerais, Goiás, Tocantins e Distrito Federal, dispõem por meio da Portaria $n^{\circ} 114 / 2016$, que o profissional de biologia possui competência para atuar na área de pesquisa, desenvolvimento, inovação, gestão e controle da qualidade de alimentos e bebidas.

\section{CONSIDERAÇÕES FINAIS}

Os alimentos funcionais são constituídos por substâncias bioativas que desempenham inúmeros benefícios ao organismo, contribuindo para a melhora do sistema imunológico e metabolismo. Ademais, essas substâncias são responsáveis por auxiliar no controle do diabetes, do colesterol e de outas doenças, além de suprir as necessidades diárias de proteínas, vitaminas, carboidratos e minerais.

Os benefícios dos alimentos funcionais no controle e no tratamento do DM estão vinculados à redução da absorção de glicose, da resistência a insulina, da destruição das células beta do pâncreas, contribuindo diretamente na manutenção da glicemia por meio dos compostos funcionais encontrados em diversos alimentos como a aveia, oleaginosas, probióticos, gorduras poli-insaturadas (Ômega 3) e soja.

Além disso, sabe-se que alimentos ricos em fibras e amidos resistentes, como por exemplo, a casca de maracujá, a batata yacon e a banana verde são muito importantes, contribuindo no retardo do processo de absorção da glicose no sangue, auxiliando assim, no controle da glicemia.

Portanto, é evidente que a opção pela alimentação funcional é essencial na qualidade de vida de todas as pessoas diabéticas, por beneficiar seu organismo, e consequentemente, o metabolismo, em razão de todas as melhorias oriundas destes alimentos. Em virtude disto, propõe-se a elaboração de uma cartilha alimentar ilustrativa sobre os alimentos avaliados nesse trabalho.

Nesse contexto, o Biólogo pode e deve atuar diretamente nas pesquisas relacionadas aos alimentos funcionais, sendo um profissional apto para o desenvolvimento de pesquisas científicas. Em sua 
vasta área de atuação, é possível a execução de pesquisas vinculadas a essa temática, como também a outros temas relacionados à qualidade de vida como um todo. Desta forma, o biólogo é peça fundamental no crescimento da ciência.

\section{REFERÊNCIAS}

Agência Nacional de Vigilância Sanitária (ANVISA). Alimentos funcionais, 2016. Disponível em: <http://portal.anvisa.gov.br/informacoes-tecnicas13>. Acesso em: 06 maio 2017.

. Resolução $\mathrm{n}^{\circ} \mathbf{1 8}$, de 30 de abril de 1999. Disponível em: <http://www.anvisa.gov.br/anvisalegis/resol/18_99.htm>. Acesso em: 10 jul. 2017.

Associação Nacional de Atenção ao Diabetes (ANAD). Remédio para Diabetes - Os mais usados no Tipo 1 e 2, 2017. Disponível em: <http://www.anad.org.br/remedio-para-diabetes-os-mais-usados-notipo-1-e-2/>. Acesso em: 03 nov. 2017.

AZEVEDO, M. J. et al. Diabetes Melito: Diagnóstico, Classificação e Avaliação do Controle Glicêmico. Arquivos Brasileiros de Endocrinologia \& Metabologia. vol.46 n.1 São Paulo Feb. 2002. https://doi.org/10.1590/S0004-27302002000100004

BASHO, S. M.; BIN, M. C. Propriedades dos alimentos funcionais e seu papel na prevenção e controle da hipertensão e diabetes. Interbio v. 4 n. 12010 - ISSN 1981-3775.

BENTO, A.; BAPTISTA, H.; OLIVEIRA, F. Malformações congênitas do pâncreas: um caso clínico. Revista da Associação Médica Brasileira, Coimbra, Portugal. v. 59, n. 1, p. 35-39, 2013. https://doi.org/10.1590/S0104-42302013000100009

BERTOLA, E.; MENEZES, H. apud D'AMBROSIO, O. Mangia che te fa bene. Jornal UNESP, 2001. Disponível em: <http://www.unesp.br/aci/jornal/160/especial.htm>. Acesso em: 13 out. 2017.

BRASIL, F.; PONTAROLO, R.; CORRER, C. J. Qualidade de vida em adultos com diabetes tipo 1 e validade do DQOL-Brasil. Revista de Ciências Farmacêuticas Básica e Aplicada, Curitiba, PR, Brasil. v. 35, n. 1, p. 105-112, 2014.

BRASIL - Ministério da Saúde. Estratégias para o cuidado da pessoa com doença crônica Diabetes Mellitus, 2013. (Cadernos de Atenção Básica, $n^{\circ} 36$ ). Brasília (DF). Disponível em: <http://bvsms.saude.gov.br/bvs/publicacoes/

estrategias_cuidado_pessoa_diabetes_mellitus_cab36.pdf>. Acesso em: 07 maio 2017.

Técnicos

Gestação de alto risco: manual técnico. Brasília (DF), (Série A. Normas e Manuais <http://bvsms.saude.gov.br/bvs/publicacoes/gestacao_alto_risco.pdf>. Acesso em: 30 abr. 2017.

$\begin{array}{ccccc}\text { Política Nacional de Alimentação e Nutrição. Brasília (DF), (Secretaria de Atenção à } \\ \text { Saúde. } & \text { Departamento de Atenção } \quad \text { Básica), } 2013 \text {. Disponível em: }\end{array}$ <http://bvsms.saude.gov.br/bvs/publicacoes/politica_nacional_alimentacao_nutricao.pdf>. Acesso em: 07 maio 2017.

BRITO, G. M. G. et al. Qualidade de vida, conhecimento e atitude após programa educativo para Diabetes. Acta Paulista de Enfermagem, Aracaju, SE, Brasil; Ribeirão Preto, SP, Brasil. v. 29, n. 3, p. 298-306, 2016. https://doi.org/10.1590/1982-0194201600042

CAMARGO, A. C. Nutrição Funcional e Diabetes. Hospital A. C. Camargo, 2017. Disponível em: <http://www.accamargo.org.br/files/pdf/oficina-culinaria/adulto/nutricao-funcional-de-diabetes.pdf>.

Acesso em: 15 ago. 2017.

CARVALHO, G.; PERUCHA V. P. Benefícios dos alimentos funcionais na prevenção do diabete melito tipo 2. Nutrição Brasil. v. 14, n. 3, p. 156-160, 2015.

Conselho Federal de Biologia (CFBio). Resolução n² 2, de 5 de março de 2002: Aprova o Código de Ética do Profissional Biólogo, 2014. Disponível em: <http://www.cfbio.gov.br/artigos/RESOLUcaON\%C2\%BA-2-DE-5-DE-MARcO-DE-2002>. Acesso em: 23 out. 2017.

Resolução $\mathrm{n}^{\circ}$ 227/2010, de 18 de agosto de 2010. Disponível em: <http://www.cfbio.gov.br/area-de-atuacao>. Acesso em: 03 nov. 2017.

DOI: http://dx.doi.org/10.14393/Hygeia17055287 $\quad$ Hygeia $\quad$ v.17 $\quad$ p. $26-44, \quad 2021$ página 40


Conselho Regional de Biologia Da $4^{a}$ Região (CRBio-04). Portaria CRBio-04 no 114/2016. Disponível em: <http://www.crbio04.gov.br/images/portaria_114_2016.pdf>. Acesso em: 07 nov. 2017.

COSTA, R. Tabela simplificada do teor de fibras nos alimentos. (IMeN) Instituto de Metabolismo e Nutrição, 2014. Disponível em: <http://www.nutricaoclinica.com.br/2014-05-15-19-3947/profissionais/25-alimentos-funcionais-fibras/412-tabela-simplificada-do-teor-de-fibras-nosalimentos>. Acesso em: 02 set. 2017.

D'AMBROSIO, O. Mangia che te fa bene. Jornal UNESP, 2001. Disponível em: <http://www.unesp.br/aci/jornal/160/especial.htm>. Acesso em: 13 out. 2017.

DINIZ, F. XXI Ciência para a vida: nutrição e saúde: um novo olhar sobre a produção de alimentos. Área de Informação da Sede - Outras publicações técnicas (INFOTECA-E), 2014. Disponível em: <https://www.infoteca.cnptia.embrapa.br/infoteca/handle/doc/994835>. Acesso em: 23 out. 2017

EASD; ADA. Is There an Optimal Diet for Patients With Type 2 Diabetes? Yes, the One That Works for Them! Jeremy D Krebs, Amber Parry-Strong. British Journal of Diabetes and Vascular Disease. v.13, n.2, p.60-66, 2013. https://doi.org/10.1177/1474651413479040

EMPRESA BRASILEIRA DE PESQUISA AGROPECUÁRIA (EMBRAPA). XXI Ciência para a vida: nutrição e saúde: um novo olhar sobre a produção de alimentos. Área de Informação da Sede Outras publicações técnicas (INFOTECA-E), 2014. Disponível em: <https://www.infoteca.cnptia.embrapa.br/infoteca/handle/doc/994835>. Acesso em: 23 out. 2017.

FRANÇA, E. L. et al. Semelhança de alimentos funcionais e biomateriais com relação à tolerância imunológica. Rev. Simbio-Logias, v.3, n. 4, p. 118-134, 2010.

FREITAS, M. C. F.; FOSS, M. C. Cetoacidose diabética e estado hiperglicêmico hiperosmolar. Medicina, Ribeirão Preto, 36: p. 389-393, abr./dez. 2003. https://doi.org/10.11606/issn.21767262.v36i2/4p389-393

GONÇALVES, K. et al. Aspectos psicofisiológicos relacionados com o diabetes tipo 2 e o tratamento multidisciplinar. Revista Científica JOPEF. v.21, n.01, 2016.

GUYTON, A. C.; HALL, J. E. Tratado de Fisiologia Médica. 10. ed. Rio de Janeiro - RJ: Guanabara Koogan, 2002.

Instituto de Física de São Carlos - IFSC. Diabetes poderá ser diagnosticada pelo hálito, 2017. Disponível em: <http://www.ifsc.usp.br/index.php?option=com_ content\&view=article\&id=4657:chances-da-diabetes-poder-ser-diagnosticada-pelo

halito\&catid=7:noticias\&ltemid=224>. Acesso em: 07 maio 2017.

ISER, B. P. M. et al. Prevalência de diabetes autorreferido no Brasil: resultados da Pesquisa Nacional de Saúde. Epidemiol. Serv. Saúde, Brasília. v. 24, n. 2, p. 305-314, 2015. https://doi.org/10.5123/S1679-49742015000200013

MACHADO, E. R. MALDONADE, I. R. Alho negro: características e benefícios à saúde. Embrapa Hortaliças - Artigo de divulgação na mídia (INFOTECA-E). Nosso Alho, Brasília, DF, p. 28-33, maio 2016.

em:

<https://www.infoteca.cnptia.embrapa.br/infoteca/bitstream/doc/1046973/1/Alhonegrolriani.pdf>

Acesso em: 22 out. 2017.

MAGALHÃES, A. T. et al. Avaliação do risco de desenvolver diabetes Mellitus tipo 2 em população universitária. Revista Brasileira em Promoção da Saúde, Fortaleza. v. 28, n. 1, p. 5-15, 2015. https://doi.org/10.5020/18061230.2015.p5

MIRANDA, G. S. et al. Efeito do consumo da aveia e farinha da casca de maracujá sobre a glicemia e lipemia em um grupo de voluntários. Revista de Ciências Farmacêuticas Básica e Aplicada, Viçosa, Brasil. v. 35, n. 2, p. 245-250, 2014.

MOURA, R. XXI Ciência para a vida: nutrição e saúde: um novo olhar sobre a produção de alimentos. Área de Informação da Sede - Outras publicações técnicas (INFOTECA-E), 2014. Disponível em: <https://www.infoteca.cnptia.embrapa.br/infoteca/handle/doc/994835>. Acesso em: 23 out. 2017. 
MUNHOZ, M. P. et al. Nutrição e Diabetes. Revista Odontológica de Araçatuba, v. 35, n. 2, p. 6770, Julho/Dezembro, 2014.

NAKAGAKI, M. S.; MCLELLAN, K. C. P. Diabetes Tipo 2 e Estilo de Vida: o Papel do Exercício Físico na Atenção Primária e na Secundária. Saúde em Revista, Piracicaba, v. 13, n. 33, p. 67-75, 2013. https://doi.org/10.15600/2238-1244/sr.v13n33p67-75

NITZKE, J. A. Agronegócio: panorama, perspectivas e influência do mercado de alimentos certificados. Curitiba: Appris. p. 11-23, 2012.

OLIVEIRA, D. M. et al. Conhecimento da equipe de enfermagem nas complicações do diabetes mellitus em emergência. Acta Paulista de Enfermagem. v. 27, n. 6, p. 520-525, 2014. https://doi.org/10.1590/1982-0194201400085

PALAZZIN, E. P. et al. Efeito da drenagem linfática manual sobre a glicemia e a glicose urinária em pacientes com diabetes mellitus do tipo 1: estudo preliminar. Scientia Medica. v. 22, n. 2, p. 97-101, 2012.

PANAGIOTAKOS et al. 2007. Propriedades dos alimentos funcionais e seu papel na prevenção e controle da hipertensão e diabetes. Interbio v. 4 n. 1, 2010.

PATENTE, T. A. Diabetes Mellitus tipo 1 e o Pâncreas Biônico. Departamento de MicrobiologiaUniversidade de São Paulo (USP), $2017 . \quad$ Disponível em:<http://www.icb.usp.br/bmm/ext/index.php?option=com_content\&view=article\&catid=12\%3Ageral\& id=166\%3Apancreas-bionico\&lang=br>. Acesso em: 07 maio 2017.

PERIN, L.; ZANARDO, V. P. S. Benefícios dos alimentos funcionais na prevenção do diabete melito tipo 2. Nutrição Brasil. v. 14, n. 3, p. 156-160, 2015.

PFIZER - Indústria Farmacêutica. Alimentos funcionais: o que são e para que servem. 2014. Disponível em: <http://www.pfizer.com.br/noticias/Alimentos-funcionais-o-que-s\%C3\%A3o-e-paraque-servem>. Acesso em: 12 jul. 2017.

PIRES, E. M. S. G. Cetoacidose diabética em crianças e adolescentes. Sociedade Beneficente Israelita Brasileira Albert Einstein (SBIBAE), 2014.

PORTH, C. M.; MATFIN, G. Fisiopatologia. 8. ed. v. 2. Rio de Janeiro - RJ: Guanabara Koogan, 2010.

REGULA SUS - Sistema único de Saúde. Diabetes Mellitus, 2015. Disponível em: <https://www.ufrgs.br/telessauders/documentos/protocolos_resumos/endocrino_resumo_diabetes_TS RS_20160324.pdf>. Acesso em: 11 ago. 2017.

RHEINHEIMER, J. et al. Transplante de ilhotas pancreáticas humanas: revisão da literatura e implantação de um laboratório de isolamento de llhotas pancreáticas. Revista Hospital de Clínicas de Porto Alegre (HCPA), Porto Alegre, RS, Brasil, v. 30, n. 4, p. 407-418, 2010.

RODRIGUES, T. C. et al. Infecções no paciente com diabetes melito. Revista Hospital de Clínicas de Porto Alegre (HCPA), Porto Alegre, RS, Brasil. v. 30, n. 4, p. 391-399, 2010.

SALGADO, J. Alimentos funcionais. 1. ed. São Paulo - Oficina de Textos, 2017.

SANTOS, et al. Indução de Diabetes Tipo 2 por dieta hiperlipídica e baixa dose de estreptozotocina em ratas wistar. Revista da Faculdade de Medicina de Ribeirão Preto e do Hospital das Clínicas da FMRP Universidade de São Paulo. v. 45, n. 4, p. 436-444, 2012. https://doi.org/10.11606/issn.2176-7262.v45i4p436-444

SANTOS, F. L. Os alimentos funcionas na mídia: quem paga a conta. Diálogos entre ciência e divulgação científica: leituras contemporâneas [online]. Salvador: EDUFBA, p. 199-210, 2011.

Sociedade Brasileira de Diabetes (SBD). Classificação etiológica do diabetes mellitus. Diretrizes. p. 6. 2014-2015. Disponível em: <http://www.diabetes.org.br/ profissionais/images/pdf/diabetes-tipo2/002-Diretrizes-SBD-Classificacao-pg5.pdf>. Acesso em: 15 maio 2017.

Diabetes tipo 1. 2017. Disponível em: <http://www.diabetes.org.br/publico/diabetes-tipo-1>. Acesso em: 30 abr. 2017. 
Diabetes tipo 2. 2017. Disponível em: <http://www.diabetes.org.br/publico/diabetes-tipo-2>. Acesso em: 30 abr. 2017.

Diretrizes.

p. $\quad 7$

2015-2016.

Disponível em: <https://edisciplinas.usp.br/pluginfile.php/2494673/mod_resource/content/2/DIRETRIZES-SBD-20152016.pdf>. Acesso em: 09 maio 2017

Diretrizes.

9, 2014-2015

Disponível em: <http://www.diabetes.org.br/profissionais/images/pdf/diabetes-tipo-2/003-Diretrizes-SBD-Metodospg9.pdf>. Acesso em: 14 out. 2017.

Fatores de Risco. $2017 . \quad$ Disponível $\overline{<h t t p: / / w w w . d i a b e t e s . o r g . b r / p u b l i c o / d i a b e t e s / f a t o r e s-d e-r i s c o>. ~ A c e s s o ~ e m: ~} 30$ abr. 2017.

Insulina. 2017. Disponível em: <http://www.diabetes.org.br/publico/diabetes/insulina>. Acesso em: 07 maio 2017.

Tipos de Diabetes. 2017. Disponível em: <http://www.diabetes.org.br/publico/diabetes/tiposde-diabetes>. Acesso em: 30 abr. 2017.

SOUZA, C. F. et al. Pré-diabetes: diagnóstico, avaliação de complicações crônicas e tratamento. Arquivos Brasileiros de Endocrinologia \& Metabologia. 2012, p. 275-284. Disponível em: <http://www.scielo.br/pdf/abem/v56n5/a01v56n5.pdf>. Acesso em: 12 ago. 2017. https://doi.org/10.1590/S0004-27302012000500001

SOUZA, Y. Estudo sobre diabetes tipo 2 procura pacientes voluntários. Hospital de clínicas UNICAMP, 2011. Disponível em: <https://www.hc.unicamp.br/node/301>. Acesso em: 07 maio 2017.

SULZBACH, A. et al. Alimentos funcionais: a saúde que vem do 'prato'. Embrapa Uva e Vinho Fôlder / Folheto / Cartilha (INFOTECA-E), 2012. Disponível em:<https://www.infoteca.cnptia.embrapa.br/infoteca/bitstream/doc/924100/1/alimentosfuncionaisReci clandoldeias10.pdf>. Acesso em: 22 out. 2017.

TIPOS DE DIABETES. Produção de Vida \& Saúde com RENCK, A. Coordenação Rede Novo Tempo de Comunicação. Jacareí-SP. Vida e Saúde, 2017. 1 vídeo (16m30segundos). Acesso em: 28 abr. 2017.

TOLEDO, K. Estudo evidencia relação entre doenças mentais e metabólicas. Agência Fundação de Amparo à Pesquisa do Estado de São Paulo - FAPESP, 2016. Disponível em: $<$ http://agencia.fapesp.br/estudo_evidencia_relacao_entre

doencas_mentais_e_metabolicas/22626/>. Acesso em: 06 maio 2017.

TSCHIEDEL, B. Complicações crônicas do Diabetes. v. 102, n. 5. p. 7-12, Setembro/Outubro, 2014.

UNIVERSIDADE DE BRASÍLIA (UNB). XXI Ciência para a vida: nutrição e saúde: um novo olhar sobre a produção de alimentos. Área de Informação da Sede - Outras publicações técnicas (INFOTECA-E), 2014.2 Disponível em: <https://www.infoteca.cnptia.embrapa.br/infoteca/handle/doc/994835>. Acesso em: 23 out. 2017.

VASCONCELOS, H. C. A. et al. Fatores de risco para diabetes mellitus tipo 2 entre adolescentes. Revista da Escola de Enfermagem da USP, São Paulo. v. 44 n. 4, p. 881-887, 2010. https://doi.org/10.1590/S0080-62342010000400004

VENÂNCIO, R. C. C.; GUIMARÃES, G. V. Alimentação e exercício físico: o que o diabético deve saber. 2017. Disponível em: <http://www.cepe.usp.br/?tips=alimentacao-e-exercicio-fisico-o-que-odiabetico-deve-saber-2>. Acesso em: 23 out. 2017.

VIDAL, A. M. et al. A Ingestão de Alimentos Funcionais e sua contribuição para a diminuição da Incidência de doenças. Cadernos de Graduação - Ciências Biológicas e da Saúde, Aracaju. v. 1 n. 15 p. 43-52. Out. 2012.

ZAPAROLLI et al. Alimentos funcionais no manejo da diabetes mellitus. Revista Ciência \& Saúde, Porto Alegre. v. 6, n. 1, p. 12-17, 2013. https://doi.org/10.15448/1983-652X.2013.1.11471

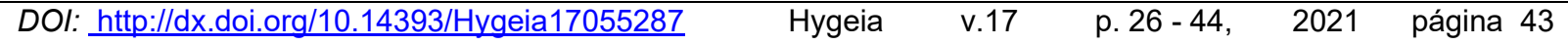


ZERAIK, M. L. et al. Maracujá: um alimento funcional? Revista Brasileira de Farmacognosia Brazilian Journal of Pharmacognosy. v.20, n.3, p. 459-471, 2010. https://doi.org/10.1590/S0102$\underline{695 \times 2010000300026}$ 